\title{
Uniqueness of Clearing Payment Matrices in Financial Networks
}

Citation for published version (APA):

Csóka, P., \& Herings, P. J-J. (2021). Uniqueness of Clearing Payment Matrices in Financial Networks. Maastricht University, Graduate School of Business and Economics. GSBE Research Memoranda No. 014 https://doi.org/10.26481/umagsb.2021014

Document status and date:

Published: 20/09/2021

DOI:

10.26481/umagsb.2021014

Document Version:

Publisher's PDF, also known as Version of record

\section{Please check the document version of this publication:}

- A submitted manuscript is the version of the article upon submission and before peer-review. There can be important differences between the submitted version and the official published version of record.

People interested in the research are advised to contact the author for the final version of the publication, or visit the DOI to the publisher's website.

- The final author version and the galley proof are versions of the publication after peer review.

- The final published version features the final layout of the paper including the volume, issue and page numbers.

Link to publication

\footnotetext{
General rights rights.

- You may freely distribute the URL identifying the publication in the public portal. please follow below link for the End User Agreement:

www.umlib.nl/taverne-license

Take down policy

If you believe that this document breaches copyright please contact us at:

repository@maastrichtuniversity.nl

providing details and we will investigate your claim.
}

Copyright and moral rights for the publications made accessible in the public portal are retained by the authors and/or other copyright owners and it is a condition of accessing publications that users recognise and abide by the legal requirements associated with these

- Users may download and print one copy of any publication from the public portal for the purpose of private study or research.

- You may not further distribute the material or use it for any profit-making activity or commercial gain

If the publication is distributed under the terms of Article $25 \mathrm{fa}$ of the Dutch Copyright Act, indicated by the "Taverne" license above, 


\section{Maastricht University}

Péter Csóka,

P. Jean-Jacques Herings

Uniqueness of Clearing Payment Matrices in Financial Networks

$\mathrm{RM} / 21 / 014$

ISSN: $2666-8807$

\section{GSBE}

Maastricht University School of Business and Economics

Graduate School of Business and Economics

P.O Box 616

NL-6200 MD Maastricht

The Netherlands 


\title{
Uniqueness of Clearing Payment Matrices in Financial Networks*

\author{
Péter Csóka ${ }^{\dagger} \quad$ P. Jean-Jacques Herings ${ }^{\ddagger}$
}

September 8, 2021

\begin{abstract}
We study bankruptcy problems in financial networks in the presence of general bankruptcy laws. The set of clearing payment matrices is shown to be a lattice, which guarantees the existence of a greatest and a least clearing payment. Multiplicity of clearing payment matrices is both a theoretical and a practical concern. We present a new condition for uniqueness that generalizes all the existing conditions proposed in the literature. Our condition depends on the decomposition of the financial network into strongly connected components. A strongly connected component which contains more than one agent is called a cycle and the involved agents are called cyclical agents. If there is a cycle without successors, then one of the agents in such a cycle should have a positive endowment. The division rule used by a cyclical agent with a positive endowment should be positive monotonic and the rule used by a cyclical agent with a zero endowment should be strictly monotonic. Since division rules involving priorities are not positive monotonic, uniqueness of the clearing payment matrix is a much bigger concern for such division rules than for proportional ones. We also show how uniqueness of clearing payment matrices is related to continuity of bankruptcy rules.
\end{abstract}

Keywords: Financial networks, systemic risk, bankruptcy rules, fixed points. JEL Classification: C71, G10.

*We would like to thank László Á. Kóczy, Péter Kondor, Miklós Pintér, Attila Tasnádi, participants of the 11th Annual Financial Market Liquidity Conference, and the 16th European Meeting on Game Theory for helpful comments.

${ }^{\dagger}$ Department of Finance, Corvinus University of Budapest and Centre for Economic and Regional Studies. E-mail: peter.csoka@uni-corvinus.hu. This research was supported by the Higher Education Institutional Excellence Program 2020 of the Ministry of Innovation and Technology in the framework of the 'Financial and Public Services' research project (TKP2020-IKA-02) at Corvinus University of Budapest. Péter Csóka also thanks funding from National Research, Development and Innovation Office - NKFIH, K-120035.

${ }^{\ddagger}$ Department of Economics, Maastricht university, P.O. Box 616, 6200 MD, Maastricht, The Netherlands. E-mail: P.Herings@maastrichtuniversity.nl. 


\section{Introduction}

Over the last decades, financial networks have become increasingly interconnected and the size of mutual financial obligations has become ever larger, thereby making systemic risk a more and more relevant concern. The standard analysis of systemic risk is based on the seminal work by Eisenberg and Noe (2001). This model has resulted in a large and rich literature, either extending it (Cifuentes, Ferrucci, and Shin, 2005; Shin, 2008; Rogers and Veraart, 2013; Schuldenzucker, Seuken, and Battiston, 2020), or using it to relate the number and magnitude of defaults to the network topology (Gai and Kapadia, 2010; Elliott, Golub, and Jackson, 2014; Acemoglu, Ozdaglar, and Tahbaz-Salehi, 2015; Glasserman and Young, 2015; Capponi, Chen, and Yao, 2016; Cabrales, Gottardi, and Vega-Redondo, 2017), or measuring systemic risk (Chen, Iyengar, and Moallemi, 2013; Demange, 2018). The model has been fruitfully applied to the assessment of the systemic stability of financial systems, see for instance Elsinger, Lehar, and Summer (2006) for an application to the Austrian banking system. For overviews of this stream of the literature, we refer to the excellent surveys by Glasserman and Young (2016) and Jackson and Pernoud (2021).

In the Eisenberg and Noe (2001) model, agents have endowments that include all the agents' tangible and intangible assets but exclude the claims and liabilities agents have towards the other agents. The mutual claims and liabilities between agents are given by a liability matrix. The asset value of an agent is obtained as the sum of the agent's endowments together with the payments received from the other agents who settle their liabilities. The equity of an agent is equal to the asset value minus the payments made to the other agents. It may well be that the asset value of an agent is not sufficient to cover all the agent's liabilities, in which case the agent has to default. Specific to the network setting is that the default of one agent has negative consequences for the asset value of other agents, which might result in those agents defaulting as well, a phenomenon known as contagion.

A clearing payment matrix describes how much the agents pay to each other. It needs to be consistent with the prevailing bankruptcy laws and should satisfy limited liability and priority of creditors. Limited liability imposes that the clearing payment matrix should not lead to negative equity for any of the agents. Priority of creditors is satisfied if the only circumstance under which an agent is allowed to default is when the agent has zero equity. Eisenberg and Noe (2001) consider the case where the bankruptcy law prescribes that claimants should be paid an amount that is proportional to their claims and provide sufficient conditions that lead to a uniquely determined clearing payment matrix.

Although the principle of proportionality is important in actual bankruptcy law, Moulin (2000), Chatterjee and Eyigungor (2015), and Flores-Szwagrzak(2015) argue priority to be 
another important principle. Kaminski (2000) explains that American bankruptcy law is a mixed lexicographic-proportional system. In this paper, we study the uniqueness of clearing payment matrices under general bankruptcy laws. We represent bankruptcy laws by division rules, which describe how insolvent agents should make payments to their claimants as a function of their asset value.

We present a system of equations with the property that a payment matrix is a clearing payment matrix if and only if it is a solution to the system of equations. This system is then used to establish that the set of clearing payment matrices has a lattice structure, which implies that there always exists a greatest and a least clearing payment matrix. Our research question is to find conditions such that the clearing payment matrix is unique, which implies that the greatest and least clearing payment matrices coincide.

The uniqueness of clearing payment matrices is of great theoretical and practical concern. Without uniqueness of the clearing payment matrix, bankruptcy laws together with the principles of limited liability and priority of creditors are not sufficient to pin down the payments that agents should make to each other. As argued in Jackson and Pernoud (2020), the existence of multiple clearing payment matrices contributes to the fragility of the financial system as a consequence of endogenous uncertainty. Pessimistic beliefs about the payments to be received from other agents can become self-fulfilling and lead to a credit freeze, where agents stop making payments to each other. To make things worse, as argued in Csòka and Herings (2018), under a large class of decentralized clearing processes, payments are made according to the least clearing payment matrix.

The uniqueness of the clearing payment matrix turns out to depend on the type of monotonicity of the division rules. Strict monotonicity requires that an increase in asset value of a defaulting agent leads to higher payments to all claimants with a non-zero claim. Positive monotonicity weakens strict monotonicity and requires that an increase in asset value of a defaulting agent leads to higher payments to all claimants receiving a positive payment at the original asset value. Proportional division rules are strictly monotonic, but priority division rules are not even positive monotonic.

Our sufficient condition for uniqueness of the clearing payment matrix depends on the decomposition of the liability matrix into strongly connected components. A strongly connected component is a maximal set of agents such that for any two agents in the set there is a chain of liabilities from one agent to the other, i.e., all agents in a strongly connected component are successors of each other. A strongly connected component that consists of more than one agent is called a cycle. An agent that is part of a cycle is called a cyclical agent.

We demonstrate that the clearing payment matrix is unique if the following three properties are satisfied. First, every cycle without successors contains at least one agent 
with a positive endowment. Second, any cyclical agent with a positive endowment uses a positive monotonic division rule. Third, any cyclical agent with a zero endowment uses a strictly monotonic division rule. Notice that our sufficient condition for uniqueness only puts assumptions on the cyclical agents.

Our sufficient condition for uniqueness generalizes existing conditions that are found in the literature, even for the case where all agents use proportional division rules. Eisenberg and Noe (2001) assume proportional division rules and require the financial network to be regular: every agent has at least one successor with a positive endowment. Koster (2019) generalizes this finding and shows that regularity is a sufficient condition for uniqueness of the clearing payment matrix when all agents use strictly monotonic division rules. Regularity implies that in every cycle without successors there is at least one agent with a positive endowment. The other two properties required in our uniqueness condition are trivially satisfied when all agents use proportional or, more generally, strictly monotonic division rules.

Glasserman and Young (2015) also study the case of proportional division rules and obtain uniqueness by assuming the existence of an outside sector, which is such that every agent has direct or indirect liabilities to an agent in the outside sector. We show how the outside sector can be represented by a single agent in the network, who has no liabilities to other agents in the network. It then follows that there are no cycles in the network without successors. Since, moreover, proportional division rules are strictly monotonic, our uniqueness condition is trivially satisfied.

Groote Schaarsberg, Reijnierse, and Borm (2018) call a financial network hierarchical if the liability matrix can be transformed into an upper triangular matrix. They show that the clearing payment matrix is unique in hierarchical financial networks without further assumptions on the division rules. Since a financial network is hierarchical if and only if there are no cycles, their condition for uniqueness is subsumed by ours.

Our uniqueness condition is quite weak when all agents use proportional division rules, since then it only requires that in cycles without successors at least one agent has a positive endowment. On the contrary, when agents use priority division rules, we present an example with a multiplicity of clearing payment matrices even when all agents have positive endowments.

In the baseline model of Eisenberg and Noe (2001), multiplicity of clearing payment matrices has no real effects in the sense that all clearing payment matrices lead to the same values for the agents' equities. This is caused by a number of simplifying assumptions, like the absence of costs of default. Another simplifying assumption is that there is a single time period in the model, which essentially assumes that markets are complete and uncertain future endowments can be replaced by their net present values. We show by means of an 
example that in a more realistic setting with multiple time periods, multiplicity of clearing payment matrices has real effects, even in the absence of costs of default.

We conclude the paper by examining bankruptcy rules, which are defined by associating to each financial network its greatest clearing payment matrix. Continuity is an attractive property of bankruptcy rules as it implies that small changes to the financial network induce small changes in the resulting payment matrix. We show that uniqueness of clearing payment matrices is a sufficient condition for continuity of bankruptcy rules. On the other hand, we demonstrate by means of an example how multiplicity of payment matrices leads to a lack of continuity.

This paper is organized as follows. Section 2 presents the model of financial networks, the various forms of monotonicity of division rules, and the definition of a clearing payment matrix. Section 3 is devoted to the lattice structure of the set of clearing payment matrices. Section 4 presents an example to show that under priority division rules multiplicity of payment matrices can occur even when all endowments are positive. This section also presents the main result of the paper: the sufficient condition for clearing payment matrices to be unique. Section 5 discusses the relation to other conditions for uniqueness that are found in the literature. We discuss the real consequences of multiplicity of clearing payment matrices in settings with time and uncertainty in Section 6 and examine the continuity of bankruptcy rules in Section 7. Finally, Section 8 presents a short conclusion.

\section{Financial Networks}

A financial network $N$ is a quadruple $(I, z, L, d)$ with the following interpretation. The set of agents in the financial network is given by the finite set $I$. The vector $z \in \mathbb{R}_{+}^{I}$ represents the non-negative endowments of the agents, which includes all the agents' tangible and intangible assets, but excludes the claims and liabilities agents have towards each other. The liability matrix $L \in \mathbb{R}_{+}^{I \times I}$ describes the mutual claims of the agents. Its entry $L_{i j}$ is the liability of agent $i$ towards agent $j$ or, equivalently, the claim of agent $j$ on agent $i$. In general, it can occur that agent $i$ has a liability towards agent $j$ and vice versa, so it may happen that simultaneously $L_{i j}>0$ and $L_{j i}>0$. We make the normalizing assumption that $L_{i i}=0$. The total liabilities of agent $i \in I$ are denoted by $\bar{L}_{i}=\sum_{j \in I} L_{i j}$.

The determination of the payments to the agents takes place by means of division rules, $d=\left(d^{i}\right)_{i \in I}$. A division rule $d^{i}$ describes which payments agent $i$ makes to claimants in $I$ as a function of the estate $E_{i} \in \mathbb{R}_{+}$of agent $i$. More formally, the division rule of agent $i \in I$ is a function $d^{i}: \mathbb{R}_{+} \rightarrow \mathbb{R}_{+}^{I}$ such that, for every $j \in I, d_{j}^{i}\left(E_{i}\right) \leq L_{i j}$ and $\sum_{j \in I} d_{j}^{i}\left(E_{i}\right)=\min \left\{E_{i}, \bar{L}_{i}\right\}$. Since $L_{i i}=0$, it follows from the definition of a division rule that $d_{i}^{i}\left(E_{i}\right)=0$. We assume that, for every $i \in I, d^{i}$ is monotonic, i.e., for every $j \in I$, for 
every $E_{i}, E_{i}^{\prime} \in \mathbb{R}_{+}$such that $E_{i} \leq E_{i}^{\prime}$, it holds that $d_{j}^{i}\left(E_{i}\right) \leq d_{j}^{i}\left(E_{i}^{\prime}\right)$. It is well-known that if $d^{i}$ is monotonic, then it is continuous, see for instance Thomson (2003).

Next, we define additional monotonicity conditions that will be useful in the analysis of the uniqueness of clearing payment matrices. The asset value at which agent $i$ starts to make payments to an agent $j \in I$ with $L_{i j}>0$ is denoted by $\underline{a}_{i j}$, so $d_{j}^{i}\left(E_{i}\right)=0$ if $E_{i} \leq \underline{a}_{i j}$ and $d_{j}^{i}\left(E_{i}\right)>0$ if $E_{i}>\underline{a}_{i j}$.

Definition 2.1. Let $N=(I, z, L, d)$ be a financial network. The division rule $d^{i}: \mathbb{R}_{+} \rightarrow$ $\mathbb{R}_{+}^{I}$ of agent $i \in I$ is strictly monotonic if, for every $j \in I$ such that $L_{i j}>0$, for every $E_{i}, E_{i}^{\prime} \in \mathbb{R}_{+}$such that $0 \leq E_{i}<E_{i}^{\prime} \leq \bar{L}_{i}$, it holds that $d_{j}^{i}\left(E_{i}\right)<d_{j}^{i}\left(E_{i}^{\prime}\right)$. It is positive monotonic if, for every $j \in I$ such that $L_{i j}>0$, for every $E_{i}, E_{i}^{\prime} \in \mathbb{R}_{+}$such that $\underline{a}_{i j} \leq E_{i}<$ $E_{i}^{\prime} \leq \bar{L}_{i}$, it holds that $d_{j}^{i}\left(E_{i}\right)<d_{j}^{i}\left(E_{i}^{\prime}\right)$.

Strict monotonicity requires that an increase in the asset value of a defaulting agent leads to higher payments to all claimants with a non-zero claim. Positive monotonicity weakens strict monotonicity and requires that an increase in asset value of a defaulting agent leads to higher payments to all claimants receiving a positive payment at the original asset value.

Some well-known examples of division rules are the proportional rule, the priority rule, the constrained equal awards rule, and the constrained equal losses rule, defined as follows.

The division rule $d^{i}$ of agent $i \in I$ is equal to the proportional rule, if it assigns to claimant $j \in I$ the amount

$$
d_{j}^{i}\left(E_{i}\right)= \begin{cases}0, & \text { if } L_{i j}=0, \\ \min \left\{\frac{L_{i j}}{L_{i}} E_{i}, L_{i j}\right\}, & \text { otherwise. }\end{cases}
$$

Under the proportional division rule, the estate is divided in a proportional way over the claimants, up to the value of their claims.

The division rule $d^{i}$ of agent $i \in I$ is equal to a priority rule if there exists a permutation $\pi: I \rightarrow\{1, \ldots,|I|\}$ such that the amount assigned to claimant $j \in I$ is equal to

$$
d_{j}^{i}\left(E_{i}\right)=\max \left\{0, \min \left\{L_{i j}, E_{i}-\sum_{\{k \in I \mid \pi(k)<\pi(j)\}} L_{i k}\right\}\right\},
$$

where $\{k \in I \mid \pi(k)<\pi(j)\}$ is the set of agents ranked before $j$ according to $\pi$. Under the priority division rule, the claim of agent $j_{1}=\pi^{-1}(1)$ is the first one to be paid, if there is any remaining estate, i.e. $E_{i}-L_{i j_{1}}>0$, then the claim of agent $j_{2}=\pi^{-1}(2)$ is paid next, and so on.

Another example of a division rule is the constrained equal awards rule. If $E_{i}>\bar{L}_{i}$, then define $\lambda_{i}=\max _{j \in I} L_{i j}$. Otherwise, define $\lambda_{i} \in\left[0, \max _{j \in I} L_{i j}\right]$ as the unique solution 
to

$$
\sum_{j \in I} \min \left\{L_{i j}, \lambda\right\}=E_{i}
$$

The constrained equal awards rule assigns to claimant $j \in I$ the amount

$$
d_{j}^{i}\left(E_{i}\right)=\min \left\{L_{i j}, \lambda_{i}\right\}
$$

Under the constrained equal awards rule, all claimants get the same amount, up to the value of their claim.

The constrained equal losses division rule is the dual of the constrained equal awards rule and imposes that all claimants face the same loss, up to the value of their claim. If $E_{i}>\bar{L}_{i}$, then define $\mu_{i}=0$. Otherwise, define $\mu_{i} \in\left[0, \max _{j \in I} L_{i j}\right]$ as the unique solution to

$$
\sum_{j \in I} \max \left\{L_{i j}-\mu_{i}, 0\right\}=E_{i}
$$

The constrained equal losses division rule of agent $i$ assigns to claimant $j \in I$ the amount

$$
d_{j}^{i}\left(E_{i}\right)=\max \left\{L_{i j}-\mu_{i}, 0\right\}
$$

It is easily verified that the proportional division rule is strictly monotonic. The constrained equal losses rule is not strictly monotonic, but it is positive monotonic. The priority rules and the constrained equal awards rule are not even positive monotonic.

The analysis of financial networks is complicated because of the mutual liability structure and the contagion effects of default. The determination of the value of the estate $E_{i}$ of agent $i \in I$ is endogenous as this value depends on the payments that are collected from the claims agent $i$ has on the other agents.

Let $\mathcal{M}$ be the set of all matrices in $\mathbb{R}_{+}^{I \times I}$ with a zero diagonal. For $M \in \mathcal{M}$ and $i \in I$, let $M_{i} \in \mathbb{R}^{I}$ denote row $i$ of $M$. For $M_{i}, M_{i}^{\prime} \in \mathbb{R}^{I}$, we write $M_{i}<M_{i}^{\prime}$ if $M_{i j} \leq M_{i j}^{\prime}$ for all $j \in I$ and there is $j^{\prime} \in I$ such that $M_{i j^{\prime}}<M_{i j^{\prime}}^{\prime}$. Notice that the liability matrix $L$ is an element of $\mathcal{M}$.

A payment matrix $P \in \mathcal{M}$ describes the mutual payments to be made by the agents, that is, $P_{i j}$ is the monetary amount to be paid by agent $i \in I$ to agent $j \in I$. Under payment matrix $P \in \mathcal{M}$, the estate $E_{i}$ of agent $i$ is given by the asset value $a_{i}(P)$, defined as

$$
a_{i}(P)=z_{i}+\sum_{j \in I} P_{j i} .
$$


Subtracting the payments as made by an agent from his asset value yields an agent's equity. More formally, the equity $e_{i}(P)$ of an agent $i \in I$ is given by

$$
e_{i}(P)=a_{i}(P)-\sum_{j \in I} P_{i j}=z_{i}+\sum_{j \in I}\left(P_{j i}-P_{i j}\right) .
$$

It follows immediately from the above expression that the sum over agents of their equities is the same as the sum over agents of their endowments.

We now extend the notions of priority of creditors and limited liability as defined for proportional division rules by Eisenberg and Noe (2001) and feasibility for general division rules in a discrete setting by Csóka and Herings (2018) to general division rules in the continuous setting studied here.

The image $\mathcal{F}_{i}$ of division rule $d_{i}$ determines the feasible set of payments. More formally, we have

$$
\mathcal{F}_{i}=d_{i}\left(\mathbb{R}_{+}\right)=\left\{d_{i}\left(E_{i}\right) \in \mathbb{R}_{+}^{I} \mid E_{i} \in \mathbb{R}_{+}\right\}
$$

A payment matrix $P \in \mathcal{M}$ is feasible if for every $i \in I$ it holds that $P_{i} \in \mathcal{F}_{i}$. A payment matrix is feasible if every row $i$ of the matrix belongs to the feasible set of payments of agent $i$, that is, payments are made in accordance with the division rules. The set of all feasible payment matrices is denoted by $\mathcal{P}$, so

$$
\mathcal{P}=\left\{P \in \mathcal{M} \mid \forall i \in I, P_{i} \in \mathcal{F}_{i}\right\}
$$

Definition 2.2. The matrix $P \in \mathcal{M}$ is a clearing payment matrix of the financial network $N=(I, z, L, d)$ if it satisfies the following three properties:

1. Feasibility: $P \in \mathcal{P}$.

2. Limited liability: For every $i \in I, e_{i}(P) \geq 0$.

3. Priority of creditors: For every $i \in I$, if $P_{i}<L_{i}$, then $e_{i}(P)=0$.

Feasibility states that the payments are in accordance with the division rules. Limited liability requires that the total payments made by an agent do not exceed the asset value of the agent. Priority of creditors expresses that default is only allowed if equity is equal to zero. The analysis of Eisenberg and Noe (2001) corresponds to the case where all agents use the proportional division rule. Csóka and Herings (2018) address the general case for a discrete set-up. 


\section{The Lattice of Clearing Payment Matrices}

A first question is whether a clearing payment matrix always exists and, if so, whether it is unique. To address these issues, we rewrite the conditions of a clearing payment matrix as the solution to a system of equations.

The following theorem relates a clearing payment matrix to the solution of a particular system of equations.

Theorem 3.1. The payment matrix $P \in \mathcal{M}$ is a clearing payment matrix of the financial network $N=(I, z, L, d)$ if and only if it solves the following system of equations:

$$
P_{i j}=d_{j}^{i}\left(a_{i}(P)\right), \quad i, j \in I \text {. }
$$

\section{Proof.}

$(\Rightarrow)$

Let $P \in \mathcal{M}$ be a clearing payment matrix of the financial network $N$. Consider some $i \in I$. We define $P_{i}^{\prime}=d^{i}\left(a_{i}(P)\right)$. Since $P_{i} \in \mathcal{F}_{i}$ and $d^{i}$ is monotonic, it holds that either (a) $P_{i}<P_{i}^{\prime}$, or (b) $P_{i}=P_{i}^{\prime}$, or (c) $P_{i}>P_{i}^{\prime}$.

Case (a). $P_{i}<P_{i}^{\prime}$.

We have that

$$
e_{i}(P)=a_{i}(P)-\sum_{j \in I} P_{i j}>a_{i}(P)-\sum_{j \in I} P_{i j}^{\prime}=a_{i}(P)-\sum_{j \in I} d_{j}^{i}\left(a_{i}(P)\right) \geq 0,
$$

where the weak inequality follows from the definition of a division rule. From $P_{i}<P_{i}^{\prime} \in \mathcal{F}_{i}$, it follows that $P_{i}<L_{i}$. Since $e_{i}(P)>0, P$ does not satisfy priority of creditors. We conclude that Case (a) cannot occur.

Case (c). $P_{i}>P_{i}^{\prime}$.

Let $E_{i} \in\left[0, \bar{L}_{i}\right]$ be such that $P_{i}=d^{i}\left(E_{i}\right)$. From $d^{i}\left(E_{i}\right)=P_{i}>P_{i}^{\prime}=d^{i}\left(a_{i}(P)\right)$ and the monotonicity of $d^{i}$, it follows that $a_{i}(P)<E_{i}$. We have that

$$
E_{i}=\sum_{j \in I} d_{j}^{i}\left(E_{i}\right)=\sum_{j \in I} P_{i j}=a_{i}(P)-e_{i}(P) \leq a_{i}(P)
$$

where the inequality follows since $P$ satisfies limited liability. This contradicts our earlier conclusion that $a_{i}(P)<E_{i}$. It follows that Case (c) cannot occur.

We have derived that Case (b) holds, so $P_{i}=P_{i}^{\prime}=d^{i}\left(a_{i}(P)\right)$. $(\Leftarrow)$

Let $P \in \mathcal{M}$ be a solution to the system of equations

$$
P_{i j}=d_{j}^{i}\left(a_{i}(P)\right), \quad i, j \in I \text {. }
$$

1. Feasibility. It holds that $P \in \mathcal{P}$ since, for every $i \in I, P_{i}=d^{i}\left(a_{i}(P)\right)$. 
2. Limited liability. For every $i \in I$, we have that

$$
e_{i}(P)=a_{i}(P)-\sum_{j \in I} P_{i j}=a_{i}(P)-\sum_{j \in I} d_{j}^{i}\left(a_{i}(P)\right) \geq a_{i}(P)-a_{i}(P)=0,
$$

where the weak inequality follows from the definition of a division rule.

3. Priority of creditors. Assume $i \in I$ is such that $P_{i}<L_{i}$. We have that

$$
\sum_{j \in I} P_{i j}=\sum_{j \in I} d_{j}^{i}\left(a_{i}(P)\right)=\min \left\{a_{i}(P), \bar{L}_{i}\right\}=a_{i}(P)
$$

where the second equality follows from the definition of a division rule and the third equality since $P_{i}<L_{i}$, so $\sum_{j \in I} P_{i j}=\sum_{j \in I} d_{j}^{i}\left(a_{i}(P)\right)<\sum_{j \in I} L_{i j}=\bar{L}_{i}$. We have that

$$
e_{i}(P)=a_{i}(P)-\sum_{j \in I} P_{i j}=0
$$

The system of equations we use to characterize clearing payment matrices is slightly different from the one used in Eisenberg and Noe (2001) for proportional division rules and the one in Koster (2019) for general division rules. In those two papers, each $|I|$ dimensional row of the payment matrix is represented by a one-dimensional parameter, like the fraction of total liabilities that are paid in Eisenberg and Noe (2001).

A lattice is a partially ordered non-empty set in which every pair of elements has a supremum and an infimum. A complete lattice is a lattice in which every non-empty subset has a supremum and an infimum. The partial order $\leq$ on $\mathcal{M}$ is defined in the usual way: for $P, P^{\prime} \in \mathcal{M}$ it holds that $P \leq P^{\prime}$ if and only if $P_{i j} \leq P_{i j}^{\prime}$ for all $(i, j) \in I \times I$. We prove next that there always exists a least clearing payment matrix and a greatest clearing payment matrix.

Theorem 3.2. The set of clearing payment matrices of the financial network $N=(I, z, L, d)$ is a complete lattice. In particular, there exists a least clearing payment matrix $P^{-}$and a greatest clearing payment matrix $P^{+}$.

Proof. Let $\varphi: \mathcal{P} \rightarrow \mathcal{P}$ be defined by

$$
\varphi_{i j}(P)=d_{j}^{i}\left(a_{i}(P)\right), \quad P \in \mathcal{P}, i, j \in I
$$

It follows from Theorem 3.1 that $P^{*}$ is a clearing payment matrix if and only if $P^{*}$ is a fixed point of $\varphi$.

The set $\mathcal{P}$ is clearly a complete lattice. 
We show that $\varphi$ is monotonic. Let $P, P^{\prime} \in \mathcal{P}$ be such that $P \leq P^{\prime}$. For every $i \in I$, it holds that

$$
\varphi_{i}(P)=d^{i}\left(a_{i}(P)\right)=d^{i}\left(z_{i}+\sum_{j \in I} P_{j i}\right) \leq d^{i}\left(z_{i}+\sum_{j \in I} P_{j i}^{\prime}\right)=d^{i}\left(a_{i}\left(P^{\prime}\right)\right)=\varphi_{i}\left(P^{\prime}\right),
$$

where the inequality follows the fact that $d^{i}$ is monotonic.

By Tarski's fixed point theorem (Tarski, 1955), the set of fixed points of $\varphi$ is a complete lattice with respect to $\leq$. It follows that the set of fixed points has a least and a greatest element.

The literature has a number of results related to Theorem 3.2. Eisenberg and Noe (2001) have an analogous result when all agent use the proportional division rule. Csóka and Herings (2018) also prove a similar result, but in a discrete set-up and not allowing for zero endowments.

Next, as a modest generalization of a result in Groote Schaarsberg, Reijnierse, and Borm (2018), who assume that all agents use the same division rule, we show that all clearing payment matrices lead to the same amount of equity. ${ }^{1}$

Theorem 3.3. If $P$ and $P^{\prime}$ are clearing payment matrices of a financial network $N=$ $(I, z, L, d)$, then $e(P)=e\left(P^{\prime}\right)$.

Proof. Let $P^{+}$be the greatest clearing payment matrix, which exists because of Theorem 3.2 , and let $P$ be an arbitrary clearing payment matrix of $N$. Let $i \in I$. If $e_{i}(P)>0$, then

$$
0<e_{i}(P)=a_{i}(P)-\bar{L}_{i} \leq a_{i}\left(P^{+}\right)-\bar{L}_{i} \leq e_{i}\left(P^{+}\right) .
$$

If $e_{i}(P)=0$, then $e_{i}\left(P^{+}\right) \geq e_{i}(P)$ since $P^{+}$satisfies limited liability.

We have that $e(P) \leq e\left(P^{+}\right)$. From $\sum_{i \in I} e_{i}(P)=\sum_{i \in I} e_{i}\left(P^{+}\right)=\sum_{i \in I} z_{i}$ and $e(P) \leq$ $e\left(P^{+}\right)$, it follows that $e(P)=e\left(P^{+}\right)$.

The result of Theorem 3.3 depends crucially on the fact that there is no smallest unit of account. Csóka and Herings (2018) show that in discrete set-ups, for instance resulting from the presence of a smallest unit of account, equity is in general not unique.

\section{Uniqueness of Clearing Payment Matrices}

Our next research question concerns the uniqueness of a clearing payment matrix.

\footnotetext{
${ }^{1}$ Groote Schaarsberg, Reijnierse, and Borm (2018) define a division rule as a function of the estate and the vector of liabilities, so treat the vector of liabilities as a variable.
} 
Theorem 2 of Eisenberg and Noe (2001) implies that in a financial network where all agents have positive endowments and use proportional division rules, the clearing payment matrix is unique. Surprisingly, when replacing proportional division rules by priority division rules, the clearing payment matrix need not be unique as Example 4.1 demonstrates.

Example 4.1. Let $N=(I, z, L, d)$ be a financial network with three agents, $I=\{1,2,3\}$, all using the priority division rule corresponding to $\pi=(3,2,1)$. Table 1 presents the endowments, the liabilities, the least clearing payment matrix $P^{-}$, the greatest clearing payment matrix $P^{+}$, and the induced asset values and equities. The set of defaulting

\begin{tabular}{c|ccc||ccc|c|c}
$z$ & \multicolumn{3}{|c||}{$L$} & & $P^{-}$ & $a\left(P^{-}\right)$ & $e\left(P^{-}\right)$ \\
\hline 1 & 0 & 2 & 1 & 0 & 0 & 1 & 1 & 0 \\
1 & 2 & 0 & 1 & 0 & 0 & 1 & 1 & 0 \\
1 & 0 & 0 & 0 & 0 & 0 & 0 & 3 & 3 \\
$z$ & & $L$ & & & $P^{+}$ & & $a\left(P^{+}\right)$ & $e\left(P^{+}\right)$ \\
\hline 1 & 0 & 2 & 1 & 0 & 2 & 1 & 3 & 0 \\
1 & 2 & 0 & 1 & 2 & 0 & 1 & 3 & 0 \\
1 & 0 & 0 & 0 & 0 & 0 & 0 & 3 & 3
\end{tabular}

Table 1: The clearing payment matrices $P^{-}$and $P^{+}$and their induced asset values and equities in Example 4.1 .

agents are different in $P^{-}$and $P^{+}$. Whereas in $P^{-}$both agent 1 and agent 2 defaults, in $P^{+}$no agent defaults.

In Example 4.1, the solvent agent, agent 3, makes the same payments in $P^{-}$and $P^{+}$. Both defaulting agents in $P^{-}$, agents 1 and 2 , make different payments in $P^{-}$and $P^{+}$. The next two propositions generalize these insights.

Proposition 4.2. Let $N=(I, z, L, d)$ be a financial network and let $P^{-}$and $P^{+}$be the least and greatest clearing payment matrix of $N$, respectively. If $i \in I$ satisfies $P_{i}^{-}<P_{i}^{+}$, then $e_{i}\left(P^{-}\right)=e_{i}\left(P^{+}\right)=0$.

Proof. Let $i \in I$ be such that $e_{i}\left(P^{+}\right)>0$. By Theorem 3.3 it holds that $e_{i}\left(P^{-}\right)=$ $e_{i}\left(P^{+}\right)>0$. Feasibility and priority of creditors now imply that $P_{i}^{-}=P_{i}^{+}=L_{i}$. Therefore, if $i \in I$ satisfies $P_{i}^{-}<P_{i}^{+}$, then $e_{i}\left(P^{+}\right)=0$, and by Theorem 3.3, $e_{i}\left(P^{-}\right)=0$.

According to Proposition 4.2, if an agent makes different payments in two clearing payment matrices, then this agent has zero equity. The next proposition shows how differences in payments by some agents propagate in the financial network. 
Proposition 4.3. Let $N=(I, z, L, d)$ be a financial network, $P^{-}$and $P^{+}$be the least and greatest clearing payment matrix of $N$, respectively, and $i_{1} \in I$ be such that $P_{i_{1}}^{-}<P_{i_{1}}^{+}$. Let $\left(i_{1}, \ldots, i_{k^{\prime}}\right)$ be a sequence of agents in I such that, for every $k=1, \ldots, k^{\prime}-1$,

$$
\begin{aligned}
& d^{i_{k}} \text { is positive monotonic, } \\
& e_{i_{k}}\left(P^{+}\right)=0, \\
& P_{i_{k} i_{k+1}}^{+}>0 .
\end{aligned}
$$

Then, for every $k=1, \ldots, k^{\prime}-1$, it holds that $P_{i_{k} i_{k+1}}^{-}<P_{i_{k} i_{k+1}}^{+}$.

Proof. Let $E^{-}, E^{+} \in \mathbb{R}_{+}^{I}$ be such that, for every $i \in I, E_{i}^{-} \leq E_{i}^{+} \leq \bar{L}_{i}$, and

$$
\begin{aligned}
& P_{i}^{-}=d^{i}\left(E_{i}^{-}\right), \\
& P_{i}^{+}=d^{i}\left(E_{i}^{+}\right) .
\end{aligned}
$$

For every $k=1, \ldots, k^{\prime}-1$, it holds by Theorem 3.3 that $e_{i_{k}}\left(P^{-}\right)=e_{i_{k}}\left(P^{+}\right)$and, since $d^{i_{k}}$ is positive monotonic and $P_{i_{k} i_{k+1}}^{+}>0$, it holds that $E_{i_{k}}^{+}>\underline{a}_{i_{k} i_{k+1}}$.

We now show by induction that

$$
E_{i_{k}}^{-}<E_{i_{k}}^{+}, \quad k=1, \ldots, k^{\prime}-1
$$

For $k=1, E_{i_{1}}^{-}<E_{i_{1}}^{+}$follows from $P_{i_{1}}^{-}<P_{i_{1}}^{+}$.

Assume that, for some $k \leq k^{\prime}-2$, it holds that $E_{i_{k}}^{-}<E_{i_{k}}^{+}$. We show that $E_{i_{k+1}}^{-}<E_{i_{k+1}}^{+}$. Since $e_{i_{k+1}}\left(P^{-}\right)=e_{i_{k+1}}\left(P^{+}\right)=0$, it holds that

$$
\begin{aligned}
& \sum_{j \in I} d_{j}^{i_{k+1}}\left(E_{k+1}^{-}\right)=z_{i_{k+1}}+\sum_{j \in I} d_{i_{k+1}}^{j}\left(E_{j}^{-}\right), \\
& \sum_{j \in I} d_{j}^{i_{k+1}}\left(E_{k+1}^{+}\right)=z_{i_{k+1}}+\sum_{j \in I} d_{i_{k+1}}^{j}\left(E_{j}^{+}\right) .
\end{aligned}
$$

We argue that the right-hand side of (4.3) is greater than that of $(4.2)$. Since $E^{-} \leq E^{+}$, we have that

$$
d_{i_{k+1}}^{j}\left(E_{j}^{+}\right) \geq d_{i_{k+1}}^{j}\left(E_{j}^{-}\right), \quad j \in I .
$$

It holds by the induction hypothesis, positive monotonicity of $d^{i_{k}}$ and $E_{i_{k}}^{+}>\underline{a}_{i_{k} i_{k+1}}$ that

$$
d_{i_{k+1}}^{i_{k}}\left(E_{i_{k}}^{+}\right)>d_{i_{k+1}}^{i_{k}}\left(E_{i_{k}}^{-}\right) .
$$

The left-hand side of (4.3) is then also greater than that of 4.2 , so

$$
\sum_{j \in I} d_{j}^{i_{k+1}}\left(E_{k+1}^{+}\right)>\sum_{j \in I} d_{j}^{i_{k+1}}\left(E_{k+1}^{-}\right)
$$


implying that

$$
E_{i_{k+1}}^{-}<E_{i_{k+1}}^{+} \text {. }
$$

It now follows that, for every $k=1, \ldots, k^{\prime}-1, P_{i_{k} i_{k+1}}^{-}=d_{i_{k+1}}^{i_{k}}\left(E_{i_{k}}^{-}\right)<d_{i_{k+1}}^{i_{k}}\left(E_{i_{k}}^{+}\right)=P_{i_{k} i_{k+1}}^{+}$.

Proposition 4.3 makes clear that if an agent makes different payments in two clearing payment matrices and this agent makes directly or indirectly a positive payment to some other defaulting agents, then there is also multiplicity of payments by these other defaulting agents, at least when division rules are positive monotonic.

A sequence of $k^{\prime} \geq 2$ distinct agents $\left(i_{1}, \ldots, i_{k^{\prime}}\right)$ is a directed path in a matrix $M \in \mathcal{M}$ if, for every $k \in\left\{1, \ldots, k^{\prime}-1\right\}, M_{i_{k} i_{k+1}}>0$. Agent $j \in I$ is connected to agent $i \in I$ in $M$ if there is a directed path $\left(i_{1}, \ldots, i_{k^{\prime}}\right)$ in $M$ such that $i_{1}=i$ and $i_{k^{\prime}}=j$.

Let $N=(I, z, L, d)$ be a financial network. A set of agents $S \subset I$ is said to be a strongly connected component in $L$ if any two distinct agents in $S$ are connected to each other in $L$ and the set $S$ is maximal with regard to this property.

For every $i \in I$, let $O(i)$ denote the strongly connected component in $L$ to which $i$ belongs. The collection $\mathcal{O}=\{O(i) \mid i \in I\}$ is a partition of $I$. We construct the directed graph $(\mathcal{O}, D)$ by defining

$$
D=\left\{\left(O, O^{\prime}\right) \in \mathcal{O} \times \mathcal{O} \mid \exists i \in O, \exists j \in O^{\prime}, L_{i j}>0\right\},
$$

so, for two distinct elements $O, O^{\prime} \in \mathcal{O}$, there is an arc from $O$ to $O^{\prime}$ if there is $i \in O$ and $j \in O^{\prime}$ such that $L_{i j}>0$. The successors of $O \in \mathcal{O}$ in the directed graph $(\mathcal{O}, D)$ are given by the strongly connected components that are connected to $O$ in $(\mathcal{O}, D)$. The directed graph $(\mathcal{O}, D)$ has no cycles. We can therefore order the sets in $\mathcal{O}$ and write $\mathcal{O}=\left\{O_{1}, \ldots, O_{R}\right\}$, where $\left(O_{r}, O_{r^{\prime}}\right) \in D$ implies $r<r^{\prime}$. In general, this order is not uniquely determined.

An agent $i \in I$ is said to be a cyclical agent and the set $O(i)$ is said to be a cycle if $O(i)$ consists of at least two elements. Agent $i$ is cyclical if and only if there is a directed path of agents in $L$ starting at agent $i$ such that the last agent on the path has a positive liability towards agent $i$. The set of all cyclical agents is denoted by $C$.

We illustrate the directed graph $(\mathcal{O}, D)$ in Example 4.4 .

Example 4.4. Consider a financial network with thirteen agents $I=\{1,2, \ldots, 13\}$. In Figure 1, if agent $i$ has a positive liability to agent $j$, then we draw an arc from $i$ to $j$.

The collection $\mathcal{O}=\left\{O_{1}, O_{2}, O_{3}, O_{4}, O_{5}\right\}$ consists of the strongly connected components in $L$, where $O_{1}=\{1\}, O_{2}=\{2,3,4,5,6\}, O_{3}=\{7,8,12\}, O_{4}=\{9\}$, and $O_{5}=$ $\{10,11,13\}$. The arcs between the strongly connected components are given by $D=$ $\left\{\left(O_{1}, O_{3}\right),\left(O_{2}, O_{4}\right),\left(O_{2}, O_{5}\right)\right\}$. The successor of $O_{1}$ is $O_{3}$, and the successors of $O_{2}$ are $O_{4}$ and $O_{5}$. The directed graph $(\mathcal{O}, D)$ has no cycles. The sets $O_{2}, O_{3}$, and $O_{5}$ are cyclical. 

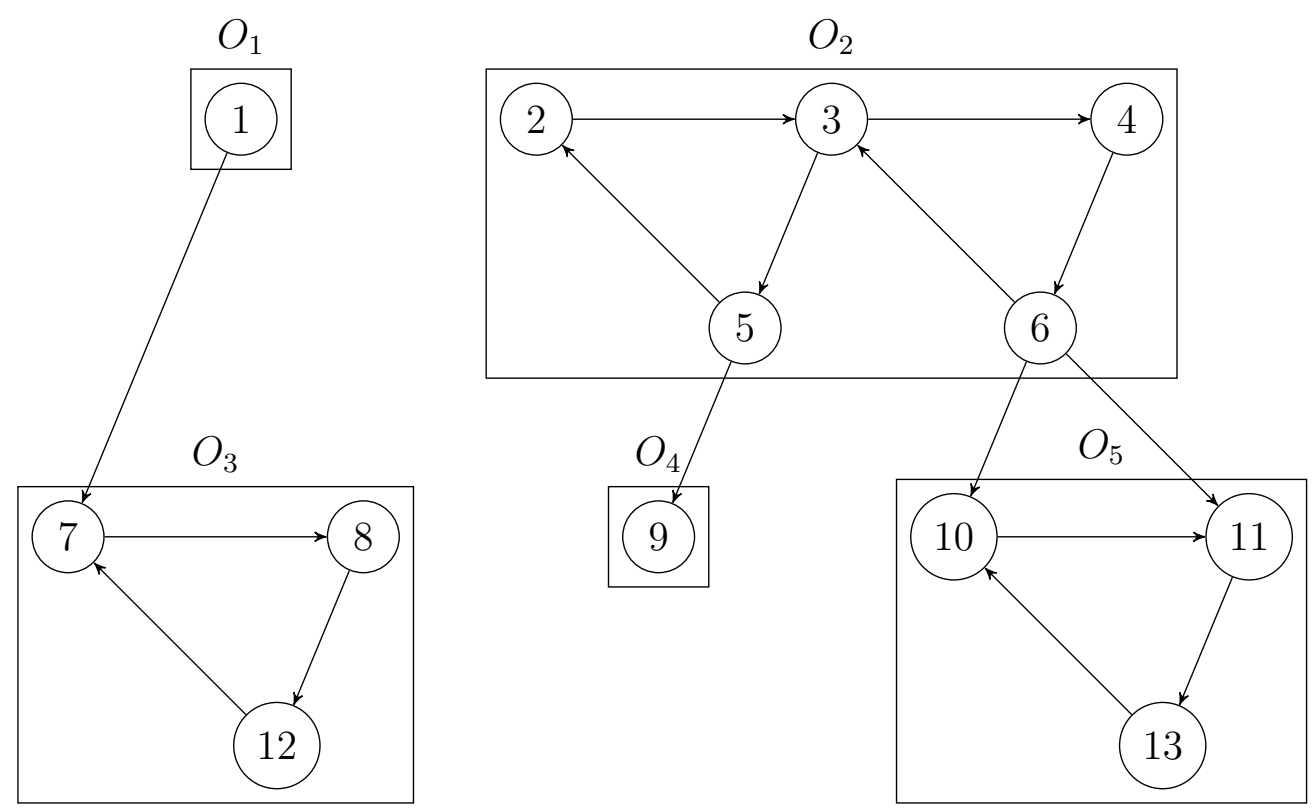

Figure 1: Agents, liabilities, and the ordered sets $\mathcal{O}$ in Example 4.4.

The set of cyclical agents is equal to $C=O_{2} \cup O_{3} \cup O_{5}=\{2,3,4,5,6,7,8,10,11,12,13\}$. For $r \in\{1,2,3,4,5\}$, agents in $O_{r}$ only have positive liabilities to agents in $O_{r^{\prime}}$ with $r^{\prime} \geq r$. In this example, we could have chosen a different order on the collection of strongly connected components. For instance, we could have ordered $O=\{9\}$ before $O^{\prime}=\{7,8,12\}$.

The next result presents a sufficient condition for the clearing payment matrix to be unique. This condition only involves the cyclical agents.

Theorem 4.5. Let $N=(I, z, L, d)$ be a financial network such that

1. if $O \in \mathcal{O}$ is a cycle and has no successors, then $\sum_{i \in O} z_{i}>0$,

2. for every $i \in C$ with $z_{i}>0$, d is positive monotonic,

3. for every $i \in C$ with $z_{i}=0, d^{i}$ is strictly monotonic.

Then $N$ has a unique clearing payment matrix.

Proof. By Theorem 3.2, $N$ has a least clearing payment matrix $P^{-}$and a greatest clearing payment matrix $P^{+}$. Let $E^{-}, E^{+} \in \mathbb{R}_{+}^{I}$ be such that, for every $i \in I, E_{i}^{-} \leq E_{i}^{+} \leq$ $\bar{L}_{i}$, and

$$
\begin{aligned}
& P_{i}^{-}=d^{i}\left(E_{i}^{-}\right), \\
& P_{i}^{+}=d^{i}\left(E_{i}^{+}\right) .
\end{aligned}
$$


By Theorem 3.3 it holds that

$$
e_{i}\left(P^{-}\right)=e_{i}\left(P^{+}\right), \quad i \in I
$$

Let $\mathcal{O}=\left\{O_{1}, \ldots, O_{R}\right\}$ be the partition of strongly connected components of $L$, where $\left(O_{r}, O_{r^{\prime}}\right) \in D$ implies $r<r^{\prime}$.

In STEP 1 we show equality of the rows in $P^{-}$and $P^{+}$that correspond to cyclical agents. Steps 2 and 3 use induction to complete the proof. STEP 2 considers the base case for rows in $O_{1}$ and STEP 3 contains the induction step.

STEP 1. For every $i \in C, P_{i}^{-}=P_{i}^{+}$.

Suppose there is $i_{1} \in C$ such that

$$
E_{i_{1}}^{-}<E_{i_{1}}^{+}
$$

We consider all the endowments and incoming payments of the agents in the cycle $O\left(i_{1}\right)$ and distinguish two cases.

Case 1. $\sum_{j \in O\left(i_{1}\right)} z_{j}+\sum_{i \in I \backslash O\left(i_{1}\right)} \sum_{j \in O\left(i_{1}\right)} P_{i j}^{+}>0$.

The set of agents $S$ consisting of $i_{1}$ together with the agents to which $i_{1}$ makes direct or indirect payments when the payment matrix is $P^{+}$is defined as

$$
S=\left\{i_{1}\right\} \cup\left\{j \in I \mid j \text { is connected to } i_{1} \text { in } P^{+}\right\} \text {. }
$$

Suppose $\sum_{j \in S} e_{j}\left(P^{+}\right)=0$. It follows that the agents in $S$ cannot have positive endowments or receive positive payments from agents outside $S$ as otherwise these resources would end up somewhere in $S$, so $\sum_{j \in S} z_{j}+\sum_{i \in I \backslash S} \sum_{j \in S} P_{i j}^{+}=0$. We have that, for every $j \in S, z_{j}=0$, and, for every $j \in S \cap O\left(i_{1}\right), d^{j}$ is strictly monotonic. Since $E_{i_{1}}^{+}>0$, the strict monotonicity of $d^{j}$ for every $j \in S \cap O\left(i_{1}\right)$ implies that $O\left(i_{1}\right) \subset S$. We have that

$$
0=\sum_{j \in S} z_{j}+\sum_{i \in I \backslash S} \sum_{j \in S} P_{i j}^{+} \geq \sum_{j \in O\left(i_{1}\right)} z_{j}+\sum_{i \in I \backslash S} \sum_{j \in O\left(i_{1}\right)} P_{i j}^{+}=\sum_{j \in O\left(i_{1}\right)} z_{j}+\sum_{i \in I \backslash O\left(i_{1}\right)} \sum_{j \in O\left(i_{1}\right)} P_{i j}^{+}>0,
$$

where the second equality follows from the fact that members of $S \backslash O\left(i_{1}\right)$ have no liabilities to agents in $O\left(i_{1}\right)$ and the strict inequality follows from the assumption of Case 1 . We have obtained a contradiction. Consequently, it follows that $\sum_{j \in S} e_{j}\left(P^{+}\right)>0$.

Subcase 1.1. $\sum_{j \in S \cap O\left(i_{1}\right)} e_{j}\left(P^{+}\right)>0$.

It holds by Proposition 4.2 that $e_{i_{1}}\left(P^{+}\right)=0$. Since all agents in $S$ are connected to $i_{1}$ in $P^{+}$, there is a finite sequence of agents $\left(i_{1}, \ldots, i_{k^{\prime}}\right)$ in $S \cap O\left(i_{1}\right)$ such that

$$
\begin{array}{rlrl}
P_{i_{k} i_{k+1}}^{+} & =d_{i_{k+1}}^{i_{k}}\left(E_{i_{k}}^{+}\right)>0, & k=1, \ldots, k^{\prime}-1, \\
e_{i_{k}}\left(P^{+}\right) & =0, & & k=1, \ldots, k^{\prime}-1, \\
e_{i_{k^{\prime}}}\left(P^{+}\right) & >0 . &
\end{array}
$$


It follows from Proposition 4.3 that $E_{i_{k^{\prime}-1}}^{-}<E_{i_{k^{\prime}-1}}^{+}$. It therefore holds that

$$
\begin{aligned}
e_{i_{k^{\prime}}}\left(P^{+}\right)-e_{i_{k^{\prime}}}\left(P^{-}\right) & =\sum_{j \in I} d_{i_{k^{\prime}}}^{j}\left(E_{j}^{+}\right)-\sum_{j \in I} d_{j}^{i_{k^{\prime}}}\left(E_{k^{\prime}}^{+}\right)-\sum_{j \in I} d_{i_{k^{\prime}}}^{j}\left(E_{j}^{-}\right)+\sum_{j \in I} d_{j}^{i_{k^{\prime}}}\left(E_{k^{\prime}}^{-}\right) \\
& =\sum_{j \in I} d_{i_{k^{\prime}}}^{j}\left(E_{j}^{+}\right)-\sum_{j \in I} d_{i_{k^{\prime}}}^{j}\left(E_{j}^{-}\right) \\
& >0
\end{aligned}
$$

where the second equality follows from $E_{i_{k^{\prime}}}^{-}=E_{i_{k^{\prime}}}^{+}=\bar{L}_{i_{k^{\prime}}}$ and the inequality follows from $E^{-} \leq E^{+}, E_{i_{k^{\prime}-1}}^{-}<E_{i_{k^{\prime}-1}}^{+}$, positive monotonicity of $d^{i_{k^{\prime}-1}}$, and $E_{i_{k^{\prime}-1}}^{+}>\underline{a}_{i_{k^{\prime}-1} i_{k^{\prime}}}$. We have obtained a contradiction to (4.4). Consequently, it follows that $E_{i_{1}}^{-}=E_{i_{1}}^{+}$, so $P_{i_{1}}^{-}=P_{i_{1}}^{+}=d^{i_{1}}\left(E_{i_{1}}^{+}\right)$.

Subcase 1.2. $\sum_{j \in S \cap O\left(i_{1}\right)} e_{j}\left(P^{+}\right)=0$.

Since $\sum_{j \in S} e_{j}\left(P^{+}\right)>0$, it holds that $S \backslash O\left(i_{1}\right) \neq \emptyset$. Let $i^{\prime} \in O\left(i_{1}\right)$ and $j^{\prime} \in S \backslash O\left(i_{1}\right)$ be such that $P_{i^{\prime} j^{\prime}}^{+}>0$. Now there is a finite path of agents $\left(i_{1}, \ldots, i_{k^{\prime}}\right)$ in $S$ such that $i_{k^{\prime}-1}=i^{\prime}$, $i_{k^{\prime}}=j^{\prime}$,

$$
\begin{aligned}
P_{i_{k} i_{k+1}}^{+} & =d_{i_{k+1}}^{i_{k}}\left(E_{i_{k}}^{+}\right)>0, & k=1, \ldots, k^{\prime}-1, \\
e_{i_{k}}\left(P^{+}\right) & =0, & k=1, \ldots, k^{\prime}-1 .
\end{aligned}
$$

Since $i_{k^{\prime}-1} \in O\left(i_{1}\right)$, it follows that $i_{1}, \ldots, i_{k^{\prime}-1} \in O\left(i_{1}\right)$. We can use Proposition 4.3 to conclude that $E_{i_{k^{\prime}-1}}^{-}<E_{i_{k^{\prime}-1}}^{+}$and therefore $P_{i^{\prime} j^{\prime}}^{-}<P_{i^{\prime} j^{\prime}}^{+}$.

We find that

$$
\begin{aligned}
\sum_{j \in S \backslash O\left(i_{1}\right)} e_{j}\left(P^{+}\right) & =\sum_{j \in S \backslash O\left(i_{1}\right)} z_{j}+\sum_{i \in O\left(i_{1}\right)} \sum_{j \in S \backslash O\left(i_{1}\right)} P_{i j}^{+}+\sum_{i \in I \backslash S} \sum_{j \in S \backslash O\left(i_{1}\right)} P_{i j}^{+} \\
& >\sum_{j \in S \backslash O\left(i_{1}\right)} z_{j}+\sum_{i \in O\left(i_{1}\right)} \sum_{j \in S \backslash O\left(i_{1}\right)} P_{i j}^{-}+\sum_{i \in I \backslash S} \sum_{j \in S \backslash O\left(i_{1}\right)} P_{i j}^{-} \\
& =\sum_{j \in S \backslash O\left(i_{1}\right)} e_{j}\left(P^{-}\right),
\end{aligned}
$$

a contradiction to Theorem 3.3 . Consequently, it follows that $E_{i_{1}}^{-}=E_{i_{1}}^{+}$, so $P_{i_{1}}^{-}=P_{i_{1}}^{+}=$ $d^{i_{1}}\left(E_{i_{1}}^{+}\right)$.

Case 2. $\sum_{j \in O\left(i_{1}\right)} z_{j}+\sum_{i \in I \backslash O\left(i_{1}\right)} \sum_{j \in O\left(i_{1}\right)} P_{i j}^{+}=0$.

It follows that $\sum_{j \in O\left(i_{1}\right)} z_{j}=0$. By the first assumption of the theorem, there is $O_{r} \in \mathcal{O}$ such that $\left(O\left(i_{1}\right), O_{r}\right) \in D$. It holds by the third assumption of the theorem that, for every $i \in O\left(i_{1}\right), d^{i}$ is strictly monotonic. Since $P_{i_{1}}^{+}>0$, we find that, for every $i \in O\left(i_{1}\right)$, $a_{i}\left(P^{+}\right)>0$, so in particular there is a positive payment to an agent in $O_{r}$. The amount $\sum_{j \in O\left(i_{1}\right)} z_{j}+\sum_{i \in I \backslash O\left(i_{1}\right)} \sum_{j \in O\left(i_{1}\right)} P_{i j}^{+}$must at least be equal to this positive payment, leading to a contradiction. Consequently, it follows that $E_{i_{1}}^{-}=E_{i_{1}}^{+}$, so $P_{i_{1}}^{-}=P_{i_{1}}^{+}=d^{i_{1}}\left(E_{i_{1}}^{+}\right)$.

Step 2. For every $i \in O_{1}, P_{i}^{-}=P_{i}^{+}$.

Case $1 . O_{1}$ is a singleton.

Let $i \in I$ be such that $O_{1}=\{i\}$. If $z_{i} \geq \bar{L}_{i}$, then feasibility and priority of creditors imply that $E_{i}^{-}=E_{i}^{+}=\bar{L}_{i}$. If $z_{i}<\bar{L}_{i}$, then limited liability and priority of creditors imply that $e_{i}\left(P^{-}\right)=e_{i}\left(P^{+}\right)=0$, so $E_{i}^{-}=E_{i}^{+}=z_{i}$. It follows in both cases that $P_{i}^{-}=P_{i}^{+}=d^{i}\left(E_{i}^{+}\right)$. 
Case 2. $O_{1}$ is a cycle.

This case follows from STEP 1.

STEP 3. Assume for some $r^{\prime}<R$, for every $r \leq r^{\prime}$, for every $i \in O_{r}, P_{i}^{-}=P_{i}^{+}$. Then, for every $i \in O_{r^{\prime}+1}, P_{i}^{-}=P_{i}^{+}$.

Case 1. $O_{r^{\prime}+1}$ is a singleton.

Let $j \in I$ be such that $O_{r^{\prime}+1}=\{j\}$. We have that $a_{j}\left(P^{-}\right)=a_{j}\left(P^{+}\right)=z_{j}+\sum_{r=1}^{r^{\prime}} \sum_{i \in O_{r}} P_{i j}^{+}$. If $a_{j}\left(P^{-}\right)=a_{j}\left(P^{+}\right) \geq \bar{L}_{j}$, then feasibility and priority of creditors imply that $E_{j}^{-}=E_{j}^{+}=$ $\bar{L}_{j}$. If $a_{j}\left(P^{-}\right)=a_{j}\left(P^{+}\right)<\bar{L}_{j}$, then limited liability and priority of creditors imply that $e_{j}\left(P^{-}\right)=e_{j}\left(P^{+}\right)=0$, so $E_{j}^{-}=E_{j}^{+}=a_{j}\left(P^{+}\right)$. It follows in both cases that $P_{i}^{-}=P_{i}^{+}=$ $d^{i}\left(E_{i}^{+}\right)$.

Case 2. $O_{r^{\prime}+1}$ is a cycle.

This case follows from STEP 1.

The sufficient condition for the clearing payment matrix to be unique in Theorem 4.5 is that (1) at least one agent in a cycle without successors has a positive endowment, (2) the division rules of cyclical agents with positive endowments are positive monotonic, and (3) the division rules of cyclical agents with zero endowments are strictly monotonic.

\section{Relation to Other Uniqueness Conditions in the Lit- erature}

The literature has found a number of conditions to obtain a unique clearing payment matrix. In this section, we show how earlier findings by Eisenberg and Noe (2001), Glasserman and Young (2015), Csóka and Herings (2017), Groote Schaarsberg, Reijnierse, and Borm (2018), and Koster (2019) are special cases of the condition presented in Theorem 4.5.

We start with the uniqueness result derived in Eisenberg and Noe (2001). Eisenberg and Noe (2001) restrict attention to proportional division rules. As mentioned before, such rules are strictly monotonic. To explain their conditions, we need the definitions of risk orbit and regular financial network.

Given a financial network $N=(I, z, L, d)$, the set consisting of agent $i \in I$ and all its successors is denoted by $\mathrm{O}^{+}(i)$, so the set $\mathrm{O}^{+}(i)$ consists of agent $i$ together with all agents $j \in I$ that are connected to agent $i$ in $L$. Eisenberg and Noe (2001) refer to $O^{+}(i)$ as the risk orbit of agent $i$. The set $O^{+}(i)$ is the union of $O(i)$ and the sets in $\mathcal{O}$ that are successors of $O(i)$ in $(\mathcal{O}, D)$. The financial network $N=(I, z, L, d)$ is said to be regular if, for every $i \in I, \sum_{j \in O^{+}(i)} z_{j}>0 . .^{2}$ Regularity rules out the situation where agent $i$ has a zero endowment and none of the agents to which agent $i$ has direct or indirect liabilities

\footnotetext{
${ }^{2}$ The formal definition of a risk orbit in Eisenberg and Noe (2001) does not make clear whether agent
} 
has a positive endowment. A sufficient condition for regularity is that all agents have positive endowments. Another sufficient condition for regularity is that one agent has a positive endowment and $\mathcal{O}$ consists of a single set, so there is a single strongly connected component.

Proposition 5.1 (Eisenberg and Noe (2001)). Let $N=(I, z, L, d)$ be a regular financial network such that all agents use the proportional division rule. Then $N$ has a unique clearing payment matrix.

Proof. If $O \in \mathcal{O}$ is a cycle and has no successors, then, for every $i \in O, O^{+}(i)=O$. Then regularity implies that $\sum_{i \in O} z_{i}>0$, so Condition (1) of Theorem 4.5 is satisfied.

Since the proportional division rule is strictly monotonic, Conditions (2) and (3) of Theorem 4.5 are satisfied.

Glasserman and Young (2015) extend the Eisenberg and Noe (2001) model by allowing agents to have liabilities to nodes outside the network. More precisely, $b_{i} \geq 0$ corresponds to the total liabilities of agent $i \in I$ to nodes outside the network. Glasserman and Young (2015) have the following condition for uniqueness of the clearing payment matrix. Every agent has positive direct or indirect liabilities to nodes outside the network. Using our notation, for every agent $i \in I$, there is $j \in O^{+}(i)$ such that $b_{j}>0$.

We continue by embedding the Glasserman and Young (2015) model into the Eisenberg and Noe (2001) framework and next reformulate their uniqueness condition. To do so, we represent the nodes outside the network by a single agent 0 . The agents inside the network are represented by the set $\{1, \ldots, n\}$. We assume, without loss of generality, that $z_{0}=0$. Agent 0 has no liabilities to nodes in the network, so, for every $i \in\{1, \ldots, n\}, L_{0 i}=0$. The liabilities of agents in the network to nodes outside the network are now replaced by liabilities to agent 0 , so, for every $i \in\{1, \ldots, n\}, L_{i 0}=b_{i}$. We obtain a financial network $N=(I, z, L, d)$ by taking $I=\{0,1, \ldots, n\}$ and, for every $i \in I$, $d^{i}$ equal to the proportional division rule. The uniqueness condition of Glasserman and Young (2015) can now be formulated as the requirement that, for every $i \in I, 0 \in O^{+}(i)$. Notice that $O^{+}(0)=\{0\}$ by construction.

Proposition 5.2 (Glasserman and Young (2015)). Let $N=(I, z, L, d)$ be a financial network such that $I=\{0,1, \ldots, n\}, z_{0}=0$, for every $i \in I, L_{0 i}=0$, and all agents use

$i$ itself is included in its risk orbit when $O(i)$ is not a cycle. The informal discussion later on in the paper suggests agent $i$ is included. Indeed, Eisenberg and Noe (2001) assert that the assumption that every agent has a positive endowment is a sufficient condition for regularity, which would not be true without the inclusion of agent $i$ in its risk orbit. Since the condition of regularity is weaker when agent $i$ is included in the risk orbit and all the proofs in Eisenberg and Noe (2001) remain valid in this case, we assume here that agent $i$ is included in its risk orbit. 
the proportional division rule. If, for every $i \in I, 0 \in O^{+}(i)$, then $N$ has a unique clearing payment matrix.

Proof. It clearly holds that $\{0\} \in \mathcal{O}$ and, by assumption, $\{0\}$ is a successor of every $O \in \mathcal{O} \backslash\{\{0\}\}$. As there are no cycles without successors, Condition (1) of Theorem 4.5 is therefore trivially satisfied.

Since the proportional division rule is strictly monotonic, Conditions (2) and (3) of Theorem 4.5 are satisfied.

The conditions of Proposition 5.1 and Proposition 5.2 are quite different. Proposition 5.1 makes sure that there are positive endowments among every agents and its successors, whereas Proposition 5.2 makes no assumption regarding the endowments, but assumes positive liabilities to a designated agent, representing the outside sector.

Groote Schaarsberg, Reijnierse, and Borm (2018) provide a condition for the case where division rules can be more general than the proportional rule. A financial network is called hierarchical if, by reordering the agents, the matrix $L$ can be transformed into an upper triangular matrix, i.e., a matrix with zeros below the diagonal.

Proposition 5.3 (Groote Schaarsberg, Reijnierse, and Borm (2018)). Let $N=(I, z, L, d)$ be a hierarchical financial network $!^{3}$ Then $N$ has a unique clearing payment matrix.

Proof. If the matrix $L$ can be written in an upper triangular form, then are are no cycles and no cyclical agents, so the conditions of Theorem 4.5 are trivially satisfied.

Even when attention is restricted to proportional division rules, the conditions of Proposition 5.3 are independent from those of Propositions 5.1 and 5.2 . Unlike Propositions 5.1 and 5.2, cycles are not allowed. On the other hand, Proposition 5.3 makes no assumptions on endowments and does not require that all agents have a positive liability to a designated agent. The proposition also applies to division rules which are not proportional.

Koster (2019) extends the regularity condition of Eisenberg and Noe (2001) from proportional division rules to strictly monotonic division rules.

Proposition 5.4 (Koster (2019)). Let $N=(I, z, L, d)$ be a regular financial network such that all agents use a strictly monotonic division rule. ${ }^{4}$ Then $N$ has a unique clearing payment matrix.

\footnotetext{
${ }^{3}$ Groote Schaarsberg, Reijnierse, and Borm (2018) require additionally that all agents use the same division rule, where a division rule is a function of the estate and the vector of liabilities.

${ }^{4}$ Koster (2019) requires additionally that all agents use the same division rule, where a division rule is a function of the estate and the vector of liabilities.
} 
Proof. If $O \in \mathcal{O}$ is a cycle and has no successors, then, for every $i \in O, O^{+}(i)=O$. Then regularity implies that $\sum_{i \in O} z_{i}>0$, so Condition (1) of Theorem 4.5 is satisfied.

Since division rules are assumed to be strictly monotonic, Conditions (2) and (3) of Theorem 4.5 are satisfied.

Proposition 5.4 shows that the conditions of Proposition 5.1 can be extended from proportional division rules to arbitrary strictly monotonic division rules. The conditions in Proposition 5.4 are clearly independent from those of Proposition 5.3 .

As we noted before, the constrained equal losses division rule does not satisfy strict monotonicity. Our generalization to positive monotonicity in Theorem 4.5 guarantees that the clearing payment matrix is unique when all agents use the constrained equal losses division rule and endowments of cyclical agents are all positive, a result that was also stated as Theorem 7.8 in Csóka and Herings (2017). This result is in stark contrast with the case of constrained equal awards division rules as will be demonstrated in Example 6.1 of Section 6. This is surprising since both division rules can be considered as each other's dual and share many common features, see Thomson (2003).

\section{Time and Uncertainty}

In settings with time and uncertainty, the Eisenberg and Noe (2001) analysis is essentially assuming that markets are complete and uncertain future endowments and liabilities can be replaced by their net present values. These assumptions are very strong. For instance, in empirically evaluating the systemic illiquidity of the British bank system, Ferrara, Langfield, Liu, and Ota (2019) need to extend the single-period Eisenberg and Noe (2001) set-up to one with multiple time periods. The next example shows that in such a more realistic set-up, multiplicity of payment matrices also matters in equity terms. Multiplicity of payment matrices is therefore payoff relevant in realistic scenarios. This example also shows that the clearing payment matrix may not be unique in a one-period model when all agents use constrained equal awards rules.

Example 6.1. We consider a setting with two time periods. In the first period, let $N=$ $(I, z, L, d)$ be a financial network with three agents $I=\{1,2,3\}$, all using constrained equal awards rules. Table 2 presents the endowments, the liabilities, the least clearing payment matrix $P^{-}$and the greatest clearing payment matrix $P^{+}$, and the induced asset values and equities.

In the second period, all agents receive an additional endowment of 1 . Moreover, agent 1 has additional liabilities to agents 2 and 3, which are due in the second period, in the amounts of 1 and 2, respectively. Unpaid liabilities of period 1 are carried over to the 


\begin{tabular}{c|ccc||ccc|c|c}
$z$ & & $L$ & & \multicolumn{2}{|c||}{$P^{-}$} & $a\left(P^{-}\right)$ & $e\left(P^{-}\right)$ \\
\hline 1 & 0 & 2 & 1 & 0 & 1 & 1 & 2 & 0 \\
1 & 2 & 0 & 1 & 1 & 0 & 1 & 2 & 0 \\
1 & 0 & 0 & 0 & 0 & 0 & 0 & 3 & 3 \\
$z$ & & $L$ & & & $P^{+}$ & & $a\left(P^{+}\right)$ & $e\left(P^{+}\right)$ \\
\hline 1 & 0 & 2 & 1 & 0 & 2 & 1 & 3 & 0 \\
1 & 2 & 0 & 1 & 2 & 0 & 1 & 3 & 0 \\
1 & 0 & 0 & 0 & 0 & 0 & 0 & 3 & 3
\end{tabular}

Table 2: The clearing payment matrices $P^{-}$and $P^{+}$and their induced asset values and equities in Example 6.1.

next period without interest. Final equity of period 1 is also carried over to period 2 without interest. When agents use the least clearing payment matrix $P^{-}$in the first period, then the situation at the beginning of the second period is given by the financial network $\widetilde{N}=(I, \widetilde{z}, \widetilde{L}, \widetilde{d})$ as described in Table 3. The financial network $\widetilde{N}$ has a unique

\begin{tabular}{c|ccc||ccc|c|c|}
$\widetilde{z}$ & \multicolumn{3}{|c||}{$\widetilde{L}$} & & $\widetilde{P}$ & $\widetilde{a}(\widetilde{P})$ & $\widetilde{e}(\widetilde{P})$ \\
\hline 1 & 0 & 2 & 2 & 0 & 1 & 1 & 2 & 0 \\
1 & 1 & 0 & 0 & 1 & 0 & 0 & 2 & 1 \\
4 & 0 & 0 & 0 & 0 & 0 & 0 & 5 & 5
\end{tabular}

Table 3: The clearing payment matrix $\widetilde{P}$ and its induced asset value and equity using constrained equal awards rules in Example 6.1 for the financial network $\tilde{N}$ resulting from the least clearing payment matrix in the first period.

clearing payment matrix $\widetilde{P}$.

We next examine the use of the greatest clearing payment matrix $P^{+}$in the first period. Table 4 presents the resulting financial network $\widehat{N}=(I, \widehat{z}, \widehat{L}, \widehat{d})$ at the beginning of the second period. The financial network $\widehat{N}$ has a unique clearing payment matrix $\widehat{P}$. We

\begin{tabular}{|c|c|c|c|c|c|c|c|c|}
\hline$\widehat{z}$ & \multicolumn{3}{|c|}{$\widehat{L}$} & \multicolumn{3}{|c|}{$\widehat{P}$} & $\widehat{a}(\widehat{P})$ & $\widehat{e}(\widehat{P})$ \\
\hline 1 & 0 & 1 & 2 & 0 & 0.5 & 0.5 & 1 & 0 \\
\hline 1 & 0 & 0 & 0 & 0 & 0 & 0 & 1.5 & 1.5 \\
\hline 4 & 0 & 0 & 0 & 0 & 0 & 0 & 4.5 & 4.5 \\
\hline
\end{tabular}

Table 4: The clearing payment matrix $\widehat{P}$ and its induced asset value and equity using constrained equal awards rules in Example 6.1 for the financial network $\widehat{N}$ resulting from the greatest clearing payment matrix in the first period.

conclude that the final equities in the second period in financial network $\widehat{N}$ and different 
from those in the financial network $\widetilde{N}$, and are therefore affected by the clearing payment matrix that is used in the first period. In fact, agent 2 benefits from the use of the greatest clearing payment matrix in the first period, the unique clearing payment matrix where agent 1 does not default in the first period.

\section{$7 \quad$ Bankruptcy Rules}

In this section, we fix the set of agents $I$ and the division rules $d$, but allow the endowments $z$ and the liability matrix $L$ to vary. To avoid confusion, we make the dependence of the division rule on the vector of liabilities explicit and write $d^{i}\left(E, L_{i}\right)$ for the division rule of agent $i \in I$. We also make the dependence on endowments of the asset value and equity explicit and write $a_{i}(z, P)$ and $e_{i}(z, P)$ for the asset value and equity of agent $i \in I$, respectively.

We assume that, for every $i \in I, d^{i}$ is continuous in $L_{i}$, an assumption that is satisfied for all commonly used division rules. The set of financial networks, denoted by $\mathcal{N}$, consists of all pairs of vectors of endowments in $\mathbb{R}_{+}^{I}$ and liability matrices in $\mathcal{M}$, so

$$
\mathcal{N}=\mathbb{R}_{+}^{I} \times \mathcal{M}
$$

We next define the bankruptcy rule $b: \mathcal{N} \rightarrow \mathcal{M}$ by associating the greatest clearing payment matrix to the financial network $N=(z, L) \in \mathcal{N}$.

Definition 7.1. Let $I$ and $d$ be given. The bankruptcy rule $b: \mathcal{N} \rightarrow \mathcal{M}$ is given by

$$
b(z, L)=P^{+}, \quad(z, L) \in \mathcal{N}
$$

where $P^{+}$is the greatest clearing payment matrix for the financial network $(z, L)$.

In general, each agent could use a different division rule. However, if a bankruptcy rule is based on the same division rule for each agent, then the name of the bankruptcy rule can be inherited from the division rules. For instance, if all agents use the constrained equal awards division rule, then we call the resulting bankruptcy rule the constrained equal awards bankruptcy rule.

We endow $\mathcal{N}$ with the standard topology, based on the Euclidean topology for endowments and liabilities. Continuity is an attractive property of a bankruptcy rule since it implies that small changes in the financial network induce small changes in the resulting payment matrix. Continuity is also used as an axiom in Csóka and Herings (2021) in order to axiomatize the proportional bankruptcy rule. The next result states that $b$ is continuous at any financial network with a unique clearing payment matrix. 
Theorem 7.2. Let $I$ and $d$ be given. Let $(\bar{z}, \bar{L}) \in \mathcal{N}$ be such that the financial network $\bar{N}=(\bar{z}, \bar{L})$ has a unique clearing payment matrix. Then $b$ is continuous at $\bar{N}$.

Proof. Let $\left(N^{n}\right)_{n \in \mathbb{N}}=\left(z^{n}, L^{n}\right)_{n \in \mathbb{N}}$ be a sequence of financial networks in $\mathcal{N}$ that converges to the financial network $\bar{N}=(\bar{z}, \bar{L})$. We have to show that the sequence of payment matrices $\left(P^{n}\right)_{n \in \mathbb{N}}$ defined by $P^{n}=b\left(z^{n}, L^{n}\right)$ converges to the payment matrix $b(\bar{z}, \bar{L})$.

The convergence of the sequence $\left(L^{n}\right)_{n \in \mathbb{N}}$ implies that it is bounded, which in turn implies that the sequence $\left(P^{n}\right)_{n \in \mathbb{N}}$ is bounded. Using the boundedness of the sequence $\left(P^{n}\right)_{n \in \mathbb{N}}$, we can assume without loss of generality that it has a limit $\bar{P} \in \mathcal{M}$. For every $n \in \mathbb{N}$, it holds by Theorem 3.1 that

$$
P_{i j}^{n}=d_{j}^{i}\left(a_{i}\left(z^{n}, P^{n}\right), L_{i}\right), \quad i, j \in I
$$

We have that

$$
\bar{P}_{i j}=\lim _{n \rightarrow \infty} P_{i j}^{n}=\lim _{n \rightarrow \infty} d_{j}^{i}\left(a_{i}\left(z^{n}, P^{n}\right), L_{i}\right)=d_{j}^{i}\left(a_{i}(\bar{z}, \bar{P}), L_{i}\right), \quad i, j \in I,
$$

where the third equality uses that $d_{j}^{i}$ and $a_{i}$ are continuous. It follows by Theorem 3.1 that $\bar{P}$ is a clearing payment matrix of the financial network $\bar{N}$. Since $\bar{N}$ has a unique clearing payment matrix by assumption, $\bar{P}$ is also the greatest clearing payment matrix and therefore equal to $b(\bar{z}, \bar{L})$ by definition of $b$.

Consider the proportional bankruptcy rule or the constrained equal losses bankruptcy rule on the domain of financial networks $(z, L)$ where the first condition of Theorem 4.5 is satisfied. By Theorem 7.2, these bankruptcy rules are continuous. Such a result was also obtained in Csóka and Herings (2017) for the special case where all initial endowments are strictly positive. They also present the following example to show that a similar result does not hold for the constrained equal awards bankruptcy rule.

Example 7.3. Consider the first period in the financial network of Example 6.1 with three agents $I=\{1,2,3\}$, each using the constrained equal awards rule. Table 5 presents the endowments, the liabilities, the payment matrix $P^{+}$resulting from the constrained equal awards bankruptcy rule, and the induced asset values and equities. Agents are all able to pay their liabilities, though agents 1 and 2 end up with zero equity.

Now, for $\varepsilon>0$, consider the financial network $N^{\varepsilon}=\left(z, L^{\varepsilon}\right)$ as displayed in Table 6 , where the liabilities of both agents 1 and 2 to agent 3 have gone up by $\varepsilon$.

Since constrained equal awards requires the same payments from agent 1 to agents 2 and 3, up to their claims, agent 1 can pay at most one unit to both agents. The same is 


\begin{tabular}{c|ccc||ccc|c|c}
$z$ & \multicolumn{3}{|c||}{$L$} & & $P^{+}$ & $a\left(z, P^{+}\right)$ & $e\left(z, P^{+}\right)$ \\
\hline 1 & 0 & 2 & 1 & 0 & 2 & 1 & 3 & 0 \\
1 & 2 & 0 & 1 & 2 & 0 & 1 & 3 & 0 \\
1 & 0 & 0 & 0 & 0 & 0 & 0 & 3 & 3
\end{tabular}

Table 5: The payment matrix, asset values, and equities resulting from constrained equal awards rules in Example 7.3 for the financial network $N=(z, L)$.

\begin{tabular}{c|ccc||cc|c|c|c}
$z$ & \multicolumn{3}{|c||}{$L^{\varepsilon}$} & & $P^{\varepsilon}$ & $a\left(z, P^{\varepsilon}\right)$ & $e\left(z, P^{\varepsilon}\right)$ \\
\hline 1 & 0 & 2 & $1+\varepsilon$ & 0 & 1 & 1 & 2 & 0 \\
1 & 2 & 0 & $1+\varepsilon$ & 1 & 0 & 1 & 2 & 0 \\
1 & 0 & 0 & 0 & 0 & 0 & 0 & 3 & 3
\end{tabular}

Table 6: The payment matrix, asset values, and equities resulting from constrained equal awards rules in Example 7.3 for the financial network $N^{\varepsilon}=\left(z, L^{\varepsilon}\right)$.

true for the payments of agent 2 to agents 1 and 3. Under these payments, agents 1 and 2 end up with zero equity and default partially on all their liabilities. We have that

$$
\lim _{\varepsilon \downarrow 0} b\left(z^{\varepsilon}, L^{\varepsilon}\right)=\lim _{\varepsilon \downarrow 0} P^{\varepsilon}=\left[\begin{array}{lll}
0 & 1 & 1 \\
1 & 0 & 1 \\
0 & 0 & 0
\end{array}\right] \neq\left[\begin{array}{lll}
0 & 2 & 1 \\
2 & 0 & 1 \\
0 & 0 & 0
\end{array}\right]=P^{+}=b(z, L),
$$

so while the financial networks $N^{\varepsilon}$ converge to $N$ when $\varepsilon$ tends to zero, the corresponding payment matrices do not converge.

The lack of continuity of $b$ in Example 7.3 is not resolved by making another selection from the set of clearing payment matrices. The financial network $N$ has many clearing payment matrices compatible with constrained equal awards rules. The greatest clearing payment matrix is equal to $P^{+}$and the least clearing payment matrix is equal to $P^{-}$, given by

$$
P^{-}=\left[\begin{array}{lll}
0 & 1 & 1 \\
1 & 0 & 1 \\
0 & 0 & 0
\end{array}\right]
$$

The following example shows that an alternative definition of the constrained equal awards bankruptcy rule that selects the least clearing payment matrix would not solve the lack of continuity.

Example 7.4. For $\varepsilon>0$, consider the financial network $N^{\varepsilon}=\left(z^{\varepsilon}, L\right)$ as displayed in Table 7. 


\begin{tabular}{|c|c|c|c|c|c|c|c|}
\hline$z^{\varepsilon}$ & \multicolumn{3}{|c|}{$L$} & \multicolumn{2}{|r|}{$P^{\varepsilon}$} & $a\left(z^{\varepsilon}, P^{\varepsilon}\right)$ & $e\left(z^{\varepsilon}, P^{\varepsilon}\right)$ \\
\hline $1+\varepsilon$ & 0 & 2 & 1 & 0 & 21 & $3+\varepsilon$ & $\varepsilon$ \\
\hline $1+\varepsilon$ & 2 & 0 & 1 & 2 & $\begin{array}{ll}0 & 1\end{array}$ & $3+\varepsilon$ & $\varepsilon$ \\
\hline 1 & 0 & 0 & 0 & 0 & $0 \quad 0$ & 3 & 3 \\
\hline
\end{tabular}

Table 7: The payment matrix, asset values, and equities resulting from the constrained equal awards rules in Example 7.4 for the financial network $N^{\varepsilon}=\left(z^{\varepsilon}, L\right)$.

The payment matrix $P^{\varepsilon}$ is the unique clearing payment matrix in the financial network $N^{\varepsilon}$ under constrained equal awards rules. The financial networks $N^{\varepsilon}$ tend to the financial network $N$ of Example 7.3 as $\varepsilon$ goes to zero. The payment matrices $P^{\varepsilon}$ are all equal to $b(z, L)$. Selecting the least clearing payment matrix for $N$ under constrained equal awards rules instead of the greatest clearing payment matrix $b(z, L)$ would then lead to a violation of continuity in this example.

\section{Conclusion}

We consider financial networks where agents are linked to each other with financial contracts. In case of bankruptcy, the payments to other agents are determined by bankruptcy law. Although the literature has almost exclusively focused on proportional division rules, in bankruptcy law certain claims are often given priority over other claims. We therefore allow for general division rules. The set of clearing payment matrices can be shown to be a lattice, so there always exists a least clearing payment matrix and a greatest clearing payment matrix. Since these clearing payment matrices may not all coincide, we are interested in conditions that guarantee uniqueness.

Uniqueness of clearing payment matrices depends heavily on the structural properties of the network of financial liabilities, which can be represented as a directed graph. We partition the network of financial liabilities into strongly connected components. A strongly connected component that consists of more than one agent is called a cycle. An agent that is part of such a component is said to be cyclical.

We provide the following sufficient condition for the clearing payment matrix to be unique: (1) for every cycle without successors at least one agent has a positive endowment, (2) the division rules of cyclical agents with positive endowments are positive monotonic, and (3) the division rules of cyclical agents with zero endowments are strictly monotonic.

Positive monotonicity is a new condition. It requires that if a defaulting agent makes a positive payment to another agent and the asset value of the former agent increases, then the payment to the latter agent increases as well. The well-known constrained equal losses division rule is positive monotonic, but its dual, the constrained equal awards division 
rule is not. The proportional division rule is strictly monotonic and therefore positive monotonic. Priority-based division rules are not positive monotonic.

Our sufficient condition for uniqueness is easily seen to imply several uniqueness conditions that have been provided before in the literature, which mostly considers only proportional division rules. One case is where all agents have positive endowments. Another where there are no cyclical agents or all agents have a positive liability to the outside sector. We show how the outside sector can be represented by an additional agent without liabilities to the other agents. We demonstrate that priority-based division rules as well as constrained equal awards division rules may lead to a multiplicity of clearing payment matrices, even when all endowments are positive.

We define bankruptcy rules by assigning the greatest clearing payment matrix to a financial network. We show that uniqueness of clearing payment matrices is closely related to the desirable property of continuity of bankruptcy rules. We show by means of an example that bankruptcy rules that are based on constrained equal awards division rules violate continuity. The violation of continuity is not repaired when defining bankruptcy rules alternatively by assigning the least clearing payment matrix to a financial network.

\section{References}

Acemoglu, D., A. Ozdaglar, and A. Tahbaz-Salehi (2015), "Systemic Risk and Stability in Financial Networks," American Economic Review, 105, 564-608.

Cabrales, A., P. Gottardi, and F. Vega-Redondo (2017), "Risk Sharing and Contagion in Networks," Review of Financial Studies, 30, 3086-3127.

Capponi, A., P.-C. Chen, And D.D. Yao (2016), "Liability Concentration and Systemic Losses in Financial Networks," Operations Research, 64, 1121-1134.

Chen, C., G. Iyengar, And C.C. Moallemi (2013), "An Axiomatic Approach to Systemic Risk," Management Science, 59, 1373-1388.

Cifuentes, R., G. Ferrucci, And H.S. Shin (2005), "Liquidity Risk and Contagion," Journal of the European Economic Association, 3, 556-566.

Chatterjee, S., And B. Eyigungor (2015), "A Seniority Arrangement for Sovereign Debt," American Economic Review, 105, 3740-3765.

CsókA, P., And P.J.J. Herings (2017), "An Axiomatization of the Proportional Rule in Financial Networks," GSBE Research Memorandum 17/001, Graduate School of Business and Economics, Maastricht University, Maastricht, Netherlands. 
CsókA, P., And P.J.J. Herings (2018), "Decentralized Clearing in Financial Networks," Management Science, 64, 4681-4699.

Csóka, P., And P.J.J. Herings (2021), "An Axiomatization of the Proportional Rule in Financial Networks," Management Science, 67, 2799-2812.

Demange, G. (2018), "Contagion in Financial Networks: A Threat Index," Management Science, 2018, 955-970.

EisenberG, L., And T.H. Noe (2001), "Systemic Risk in Financial Systems," Management Science, 47, 236-249.

Elliott, M., B. Golub, B., And M.O. Jackson (2014), "Financial Networks and Contagion," American Economic Review, 104, 3115-3153.

Elsinger, H., Lehar, A., And M. Summer (2006), "Risk Assessment for Banking Systems," Management Science, 52, 1301-1314.

Ferrara, G., S. Langfield, Z. Liu, and T. Ota (2019), "Systemic Illiquidity in the Interbank Network," Quantitative Finance, 19, 1779-1795.

Flores-Szwagrzak, K. (2015), "Priority Classes and Weighted Constrained Equal Awards Rules for the Claims Problem," Journal of Economic Theory, 160, 36-55.

Gai, P., And S. Kapadia (2010) , "Contagion in Financial Networks," Proceedings of the Royal Society of London A: Mathematical, Physical and Engineering Sciences, 466, 2401-2423.

Glasserman, P., And H.P. Young (2015), "How Likely Is Contagion in Financial Networks?," Journal of Banking and Finance, 50, 383-399.

Groote Schanrsberg, M., H. Reijnierse, and P. Borm (2018), "On Solving Mutual Liability Problems," Mathematical Methods of Operations Research, 87, 383-409.

Jackson, M.O., And A. Pernoud (2020), "Credit Freezes, Equilibrium Multiplicity, and Optimal Bailouts in Financial Networks, " Available at SSRN 3735251.

Jackson, M.O., And A. Pernoud (2021), "Systemic Risk in Financial Networks: A Survey," Annual Review of Economics, 13, 171-202.

Kaminski, M. M. (2000), "Hydraulic' rationing," Mathematical Social Sciences, 40, $131-155$. 
Koster, M. (2019), "A Note on Uniqueness of Clearing Prices in Financial Systems," Available at SSRN 3427039.

Moulin, H. (2000), "Priority Rules and Other Asymmetric Rationing Methods," Econometrica, 68, 643-684.

Rogers, L.C.G., And L.A.M. VeraArT (2013), "Failure and Rescue in an Interbank Network," Management Science, 59, 882-898.

Schuldenzucker, S., S. Seuken, and S. Battiston (2020), "Default Ambiguity: Credit Default Swaps Create New Systemic Risks in Financial Networks," Management Science, 66, 1981-1998.

Shin, H.S. (2008), "Risk and Liquidity in a System Context," Journal of Financial Intermediation, 17, 315-329.

TARski, A. (1955), "A Lattice-theoretical Fixpoint Theorem and Its Applications," $P a-$ cific Journal of Mathematics, 5, 285-309.

Thomson, W. (2003), "Axiomatic and Game-theoretic Analysis of Bankruptcy and Taxation Problems: A Survey," Mathematical Social Sciences, 45, 249-297. 